\title{
Reliability of Rapid Diagnostic Tests in the diagnosis of malaria amongst children in two communities in South West Nigeria
}

\author{
Ibrahim S Bello*, Jerome B Elusiyan, Babatunde I Awokola, Akinjide O Ogundokun, Bridget Omisore, \\ Olanrewaju Oyegbade, Samuel Anu Olowookere, Emmanuel Akintunde Abioye-Kuteyi, Joseph O Elujoba
}

From Challanges in malaria research: Core science and innovation

Oxford, UK. 22-24 September 2014

\section{Background}

Prompt treatment of malaria following adequate diagnosis helps to reduce morbidity and mortality in children. Lack of resources and adequate manpower in developing countries make malaria microscopy difficult. The Rapid Diagnostic Test kit (RDT) remains unpopular despite its availability and ease of use because of lack of local research on its effectiveness leading to over-prescription of Artemisinin Combination Therapy (ACT).

\section{Materials and methods}

A total of 132 children age range 1-9 years were screened for malaria routinely with rapid diagnostic test kits (RDTs HRP 2) and malaria microscopy at the general outpatient department of OAU Teaching Hospital as well as at a comprehensive health centre at Imesi Ile, South West Nigeria while marking the 2013 World Malaria Day. Needle prick was used to collect blood sample for thick and thin smear. Giemsa stain was used to prepare the slide for microscopic examination.

\section{Results}

A total of 132 children were recruited into the study. There were more females $(59.1 \%)$ than males $(40.9 \%)$. $35(26.5 \%)$ children tested positive while $97(73.5 \%)$ children tested negative for Plasmodium falciparum. In the Microscopy category, 35 (26.5\%) children tested positive while 97 (73.5\%) tested negative for malaria parasite. Out of the 35 children tested positive, RDT picked 33 as positive and 2 as negative, (sensitivity $=94.3 \%$ ). While out of the 97 that tested negative for microscopy, RDT picked

\footnotetext{
Department of Family Medicine, Obafemi Awolowo University Teaching
} Hospital, Ile Ife, Osun State, Nigeria

(c) 2014 Bello et al; licensee BioMed Central Ltd. This is an Open Access article distributed under the terms of the Creative Commons Attribution License (http://creativecommons.org/licenses/by/4.0), which permits unrestricted use, distribution, and reproduction in any medium, provided the original work is properly cited. The Creative Commons Public Domain Dedication waiver (http:// creativecommons.org/publicdomain/zero/1.0/) applies to the data made available in this article, unless otherwise stated.
94 as negative and 3 as positive (specificity $=96.9 \%$ ). The positive predictive value and negative predictive values are $91.7 \%$ and $97.9 \%$ respectively.

\section{Conclusions}

Rapid Diagnostic Test is an effective diagnostic tool for malaria amongst children in the study population. Primary and secondary health centres in the region should adopt Rapid Diagnostic Test in malaria diagnosis before administration of ACTs to avoid unnecessary treatment.

Published: 22 September 2014

doi:10.1186/1475-2875-13-S1-P10

Cite this article as: Bello et al:: Reliability of Rapid Diagnostic Tests in the diagnosis of malaria amongst children in two communities in South West Nigeria. Malaria Journal 2014 13(Suppl 1):P10. and take full advantage of:

- Convenient online submission

- Thorough peer review

- No space constraints or color figure charges

- Immediate publication on acceptance

- Inclusion in PubMed, CAS, Scopus and Google Scholar

- Research which is freely available for redistribution 